$$
\text { در اسة مقارنة في مؤشر القدرة الهو ائية و اللاهو ائية }
$$

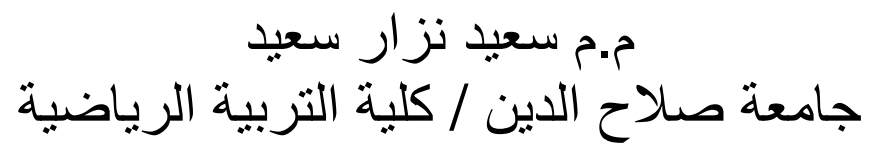

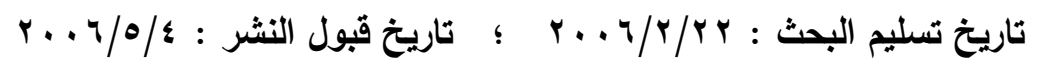

هدف البحث الى التعرف على الفرق في مؤشرة القدرة الهوائية واللاهوائية بين لاعبي كرة

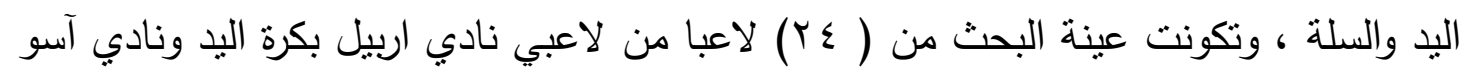

بكرة السلة وبواقع (r I) لاعب لكل فريق ، وقد استخدم الباحث المنهج الوصفي لملاعمته

وطبيعة البحث ولغرض قياس القدرة الهوائية تم استخدام اختبار هارفرد في حين نم استخدام

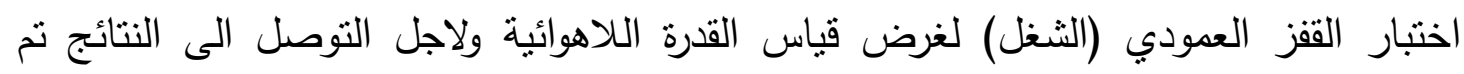

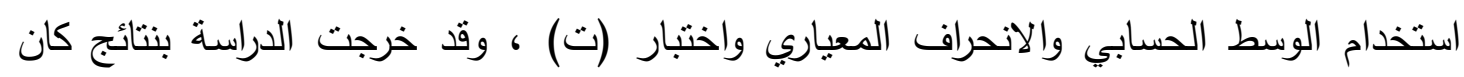
اهمها عدم وجود فروق معنوية في القدرة الهوائية واللاهوائية بين لاعبي كرة اليد والسلة الئل

\title{
A Comparative Study of Aerobic and Anaerobic Ability Among Basketball and Handball Players
}

\section{Saeed Nazar Saeed \\ University of Slahaldeen - College of Sport Education}

\section{Abstract:}

The study aims at identifying the difference of aerobic and an aerobic ability between basketball and handball players. The study sample consisted of (24) players from Erbil handball team and (12) players from Asso basketball team. Descriptive approach was used for its suitability and Harvard step test was used to measure aerobic ability. Vertical jump test was used to measure anaerobic ability. Mean, standard deviation and T-test were used as statistical tools. There were statistical significant differences between aerobic and anaerobic ability between handball and basketball players. 


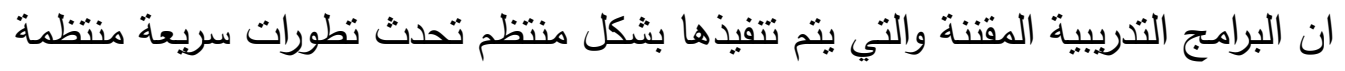

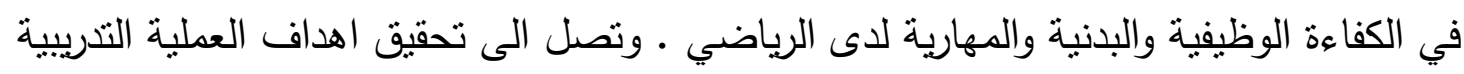

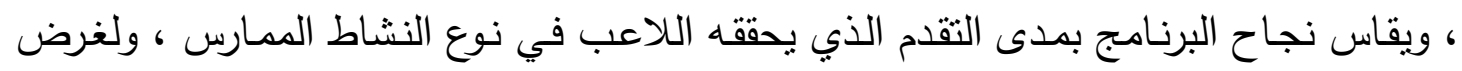

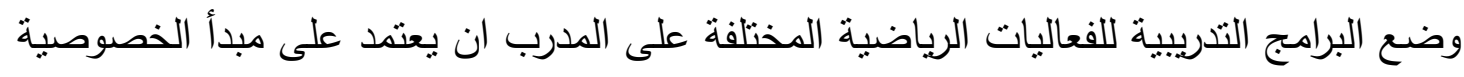

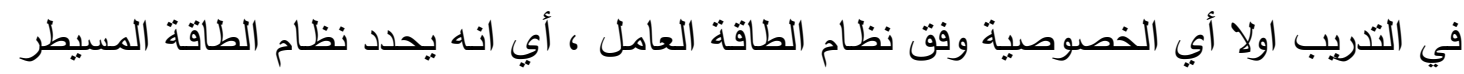

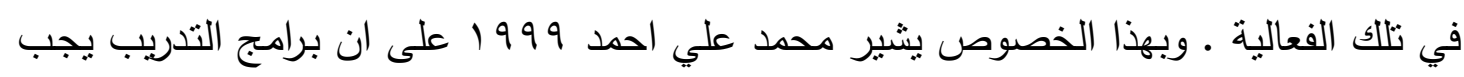

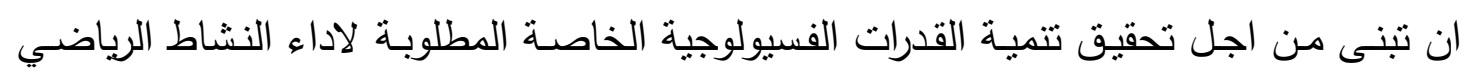

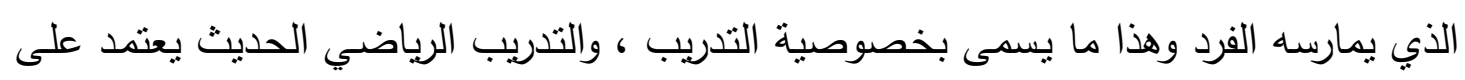

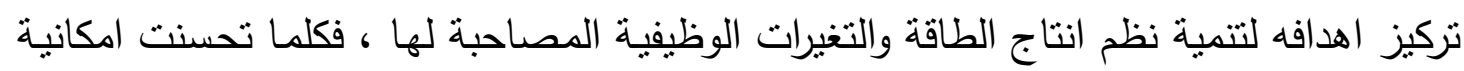

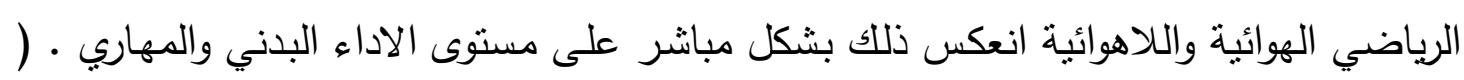
$(1)-1 \cdot: 1 r$

ويعد انتاج الطاقة في جسم الانسان من الموضوعات المهمة في مجال فسيولوجيا

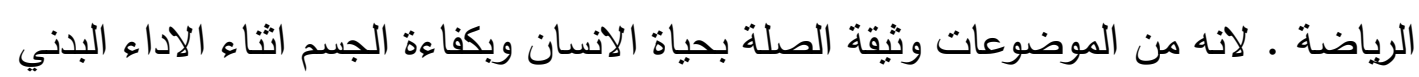

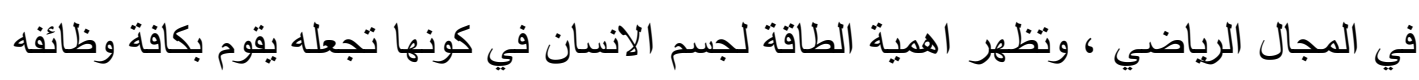

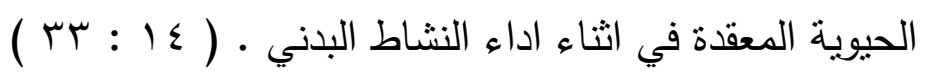
ان لعبة كرة اليد والسلة من الفعاليات الفرقية التي تتطلب اعدادادا بدنيا من اجل التب رفع كفاءة

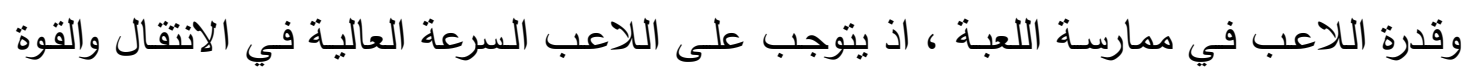

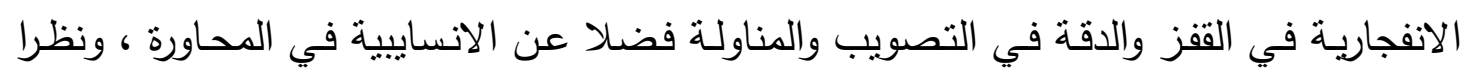

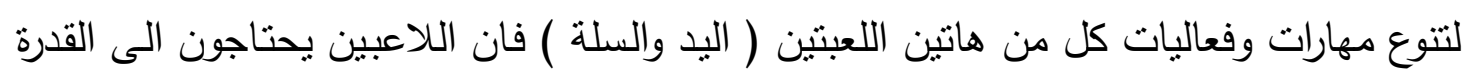

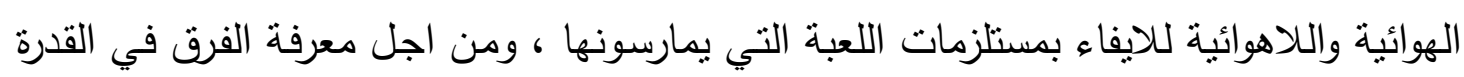

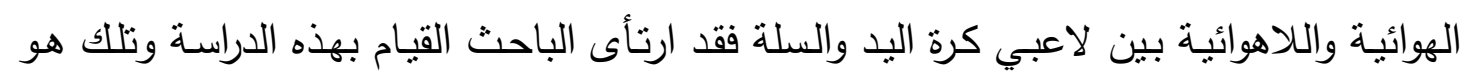
مشكلة البحث .

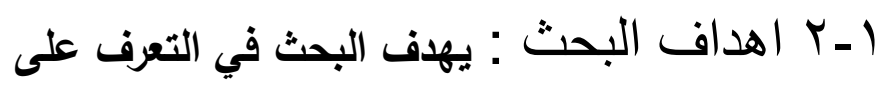

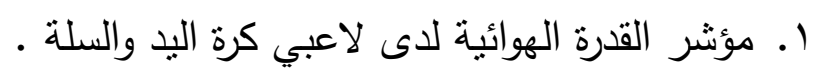

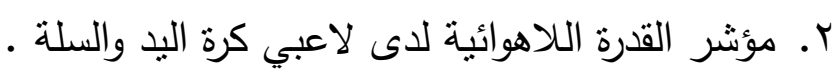

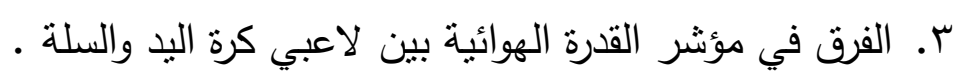

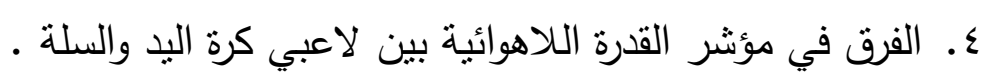




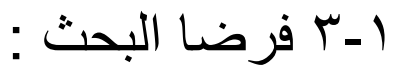

1. لاتوجد فروق ذات دلالة معنوية في مؤشر القدرة الهوائية بين لاعبي كرة اليد والسلة .

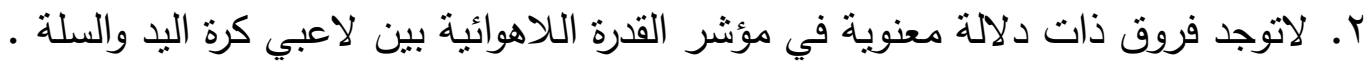

$$
\text { : 1 المجال }
$$

ا ـ المجال البشري لاعبي نادي اربيل بكرة اليد و آسو بكرة السلة .

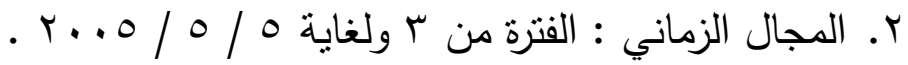

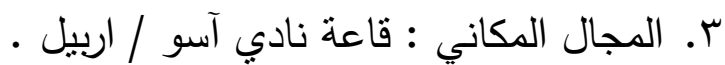

1 أه تعريف المصطلحات 1. القرة الهوائية : يعرفها محمد نصر الدين رضوان 1911 على انها المعدل الذي تسنطيع به

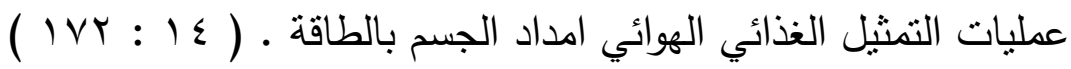
Y. القدرة اللاهوائية : يعرفها محمد نصر الدين رضوان 1991 على انها اعلى معدل يحدث

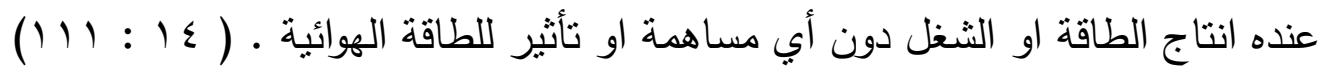

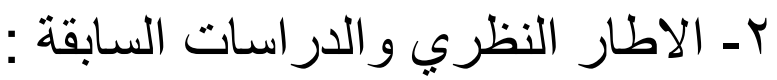

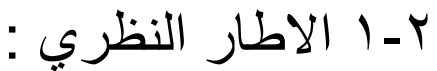
انظمة انتاج الطاقة

تعد الطاقة في جسم الانسان مصدر الانقباض العضلي ، وان مصدر الطاقة لاي نشاط

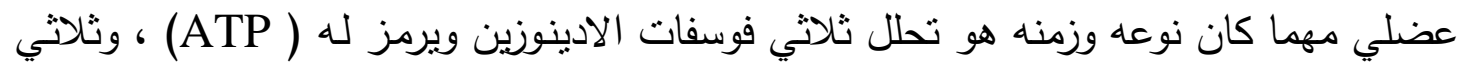

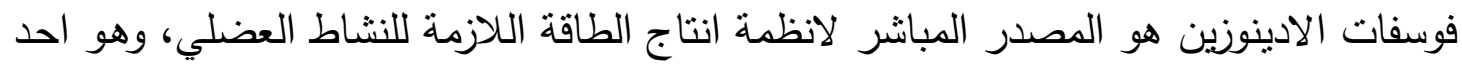

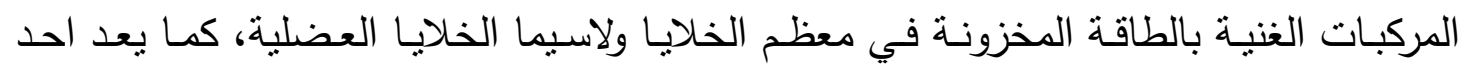

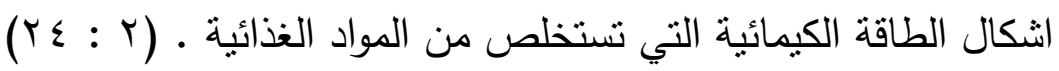

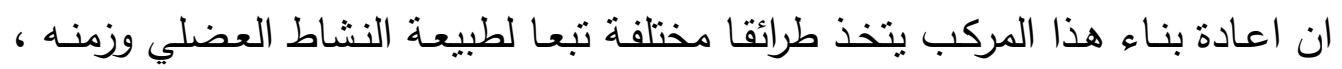
وعليه تتقسم انظمة انتاج الطاقة الى : -

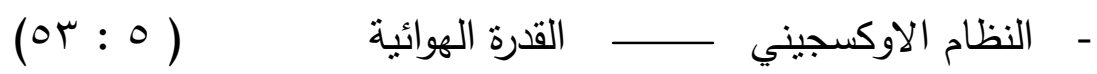
ان شدة اداء التمرين وزمنه هما اللذان يحددان نظام الطاقة العامل والمساند ، ففي الوقت

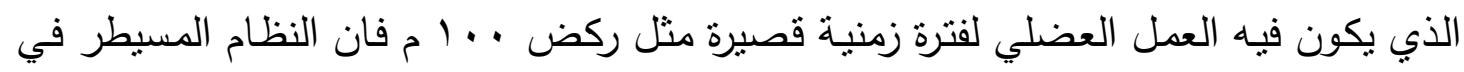


انتاج الطاقة سيكون النظام الفوسفاتي ( PC , ATP ) ، اما في حالة كون التمرين لفترة زمنية

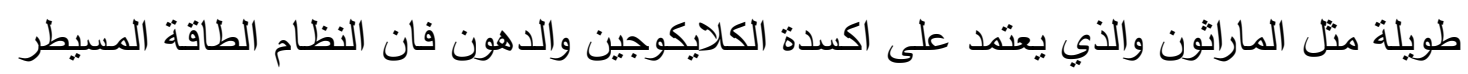
هو النظام الاوكسيجيني مال ان انظمة انتاج الطاقة وكما ذكر سابقا ثلاثة انظمة وقد تم تقسيم كل نظام من هذه

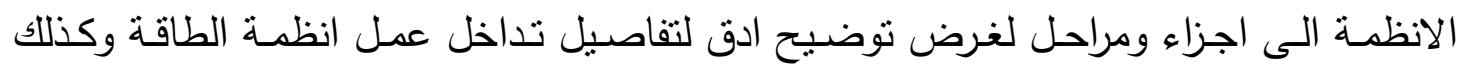

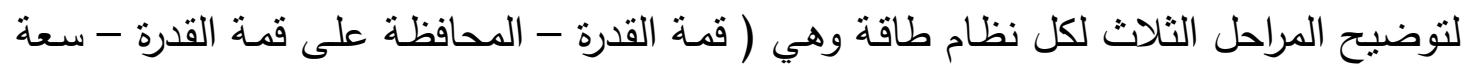

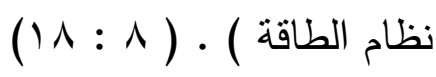

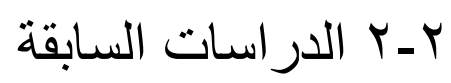

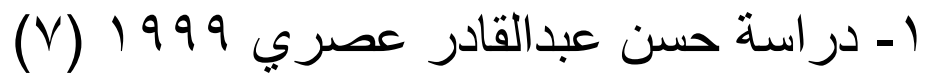
" دراسة مقارنة لبعض مؤثرات القدرة الهوائية واللاهوائية بين لاعبي الخطوط المختلفة بكرة القدم "

هدفت الدراسـة الى التعرف على بعض مؤشرات القدرة الهوائية واللاهوائية بين لاعبي

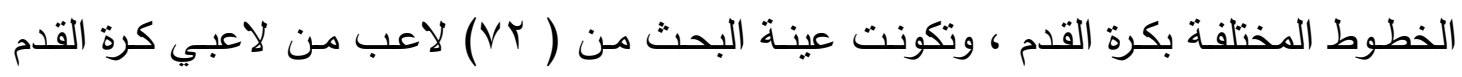

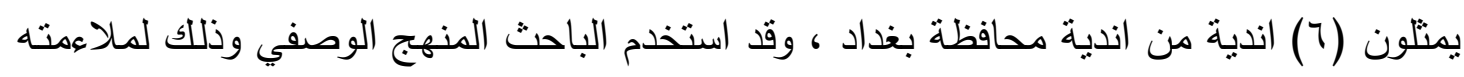

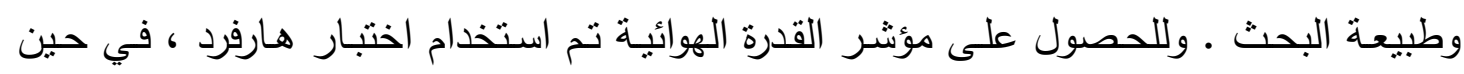

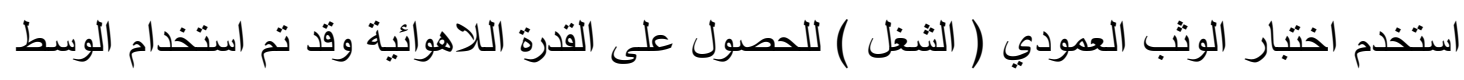

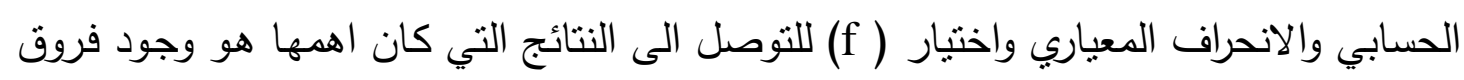

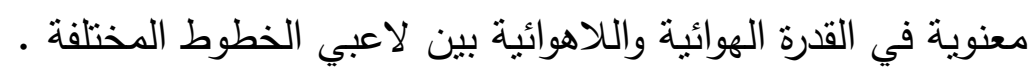

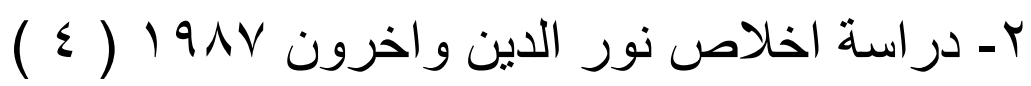
" تأثير كل من التدريب اللاهوائي والتتريب الهوائي بالحبل على الكفاءة الوظيفية لطالبات كلية التربية الرياضية " التوائ بالهيل

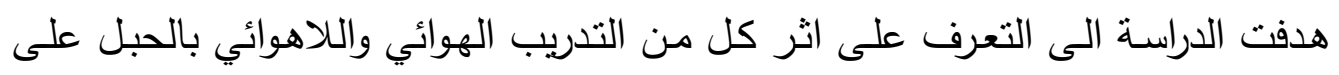

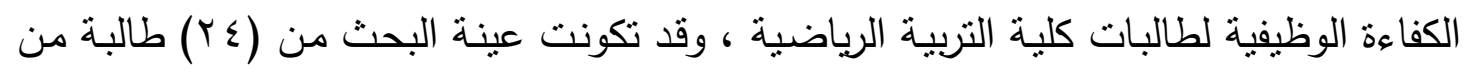

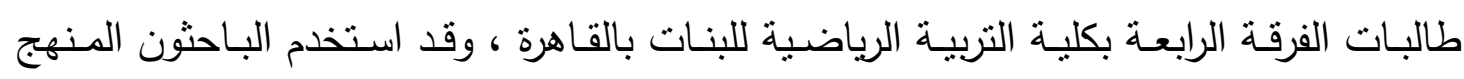

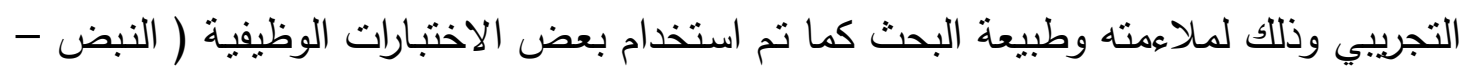
الضغط - الحد الاقصى لاستهلالك الاوكسجين ) ولغرض التوصل التهل الـى النتائج تم استخدام

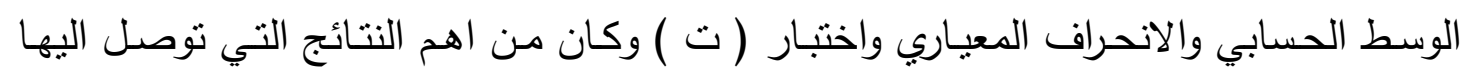

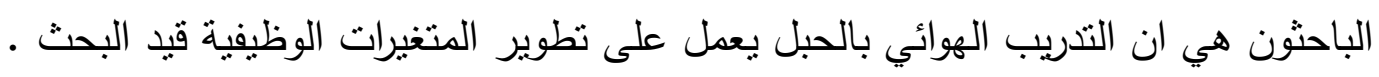




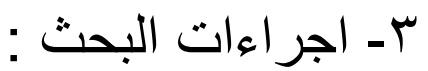

ب- ا منهج البحث : استخدم الباحث المنهج الوصفي وذلك لملاءهته وطبيعة البحث .

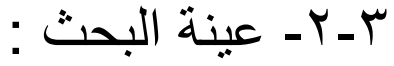

تم اختيار عينة البحث بطريقة عمدية من لاعبي اندية اربيل بكرة اليد وآسو بكرة السلة ،

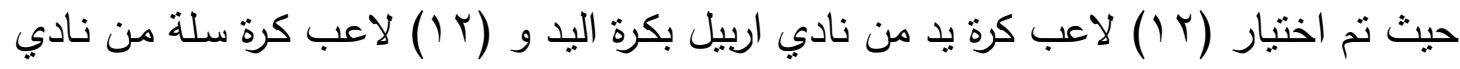

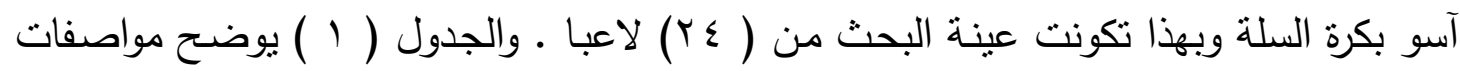

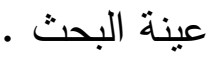

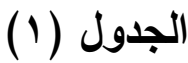

مواصفات عينة البحث

\begin{tabular}{|c|c|c|c|c|}
\hline \multicolumn{2}{|c|}{ لاعبي كرة السلة } & \multicolumn{2}{|c|}{ لاعبي كرة اليا } & \multirow{2}{*}{ مواصفات العينة } \\
\hline$\varepsilon \pm$ & س & $\varepsilon \pm$ & س & \\
\hline$r, r$ & $1 \vee 9, \varepsilon$ & $r, \varepsilon$ & $I V A, r$ & الطول /سم \\
\hline$r, \xi$ & $v 0, r$ & $\varepsilon, r$ & $V q, r$ & الوزن /كغ \\
\hline$r, \Sigma$ & $r r, q$ & $r, 1$ & rT, & العمر /سنه \\
\hline$r, T$ & $v, \cdot r$ & $r, T$ & 7,0 & العمر التدريبي /سنه \\
\hline
\end{tabular}

ب-r تكافؤ عينة البحث من اجل تكافؤ عينـة البحث في المتغيرات البدنية التي قد تؤثر على المتغيرات قيد

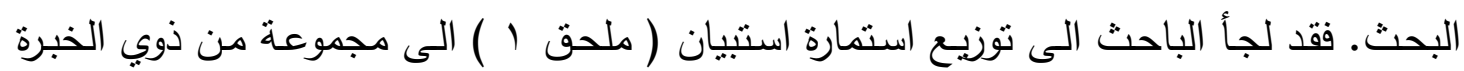

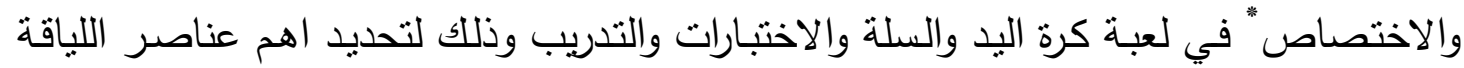
البدنية واختباراتها وبعد جمع الاستمارات وتفريغها توصل الباحث الى اهم عناصر اللياقة والبدنية

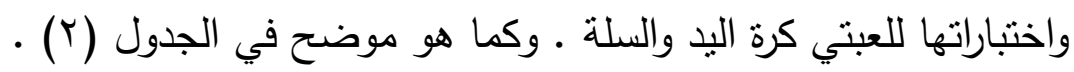

1- ا.د. ايمان حسين / كلية التربية الرياضية ، جامعة بغداد .

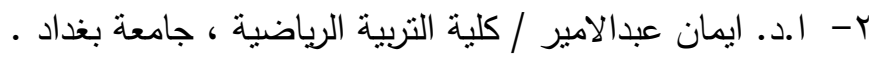

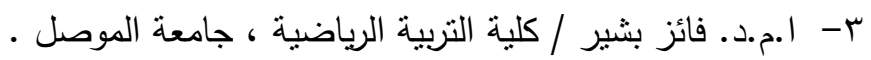

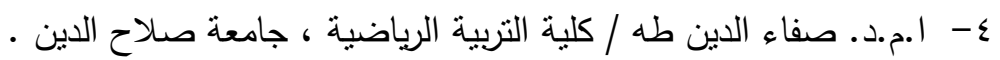

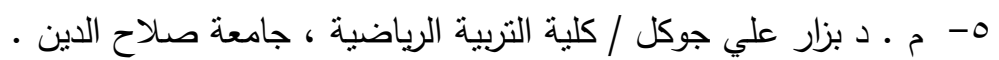




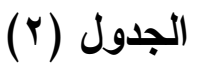

اهم عناصر اللياقة البدنية واختباراتها ومصدرها للعبتي كرة اليا والسلة

\begin{tabular}{|c|c|c|}
\hline المصدر & الاختبار & العنصر \\
\hline$\left.\left(r_{\wedge}\right): 11\right)$ & اختبار ركض • بَ م من وضع الطائر . & السرعة الانتقالية \\
\hline$(71: 1 \cdot)$ & اختبار القفز العمودي • & القوة الانفجارية للرجلين \\
\hline$(1+7: 14)$ & اختبار رمي كرة طبية زنة ب كغم من وضع الجلوس & القوة الانفجارية للذراعين \\
\hline$(\leqslant 1: 10)$ & اختبار الققز العمودي المتكرر من الوقوف ـ. & مطاولة القوة للرجلين \\
\hline$(149: 11)$ & اختبار الجري الارتدادي ع × · ام . & 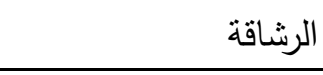 \\
\hline$($ (rqr: : ) & | اختبار الدوائر المرقمة ـ . & 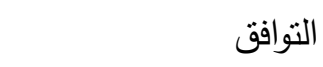 \\
\hline
\end{tabular}

بعد تحديد العناصر البدنية ذات الارتباط بلعبة كرة اليد والسلة وكذلك تحديد اختباراتها

فقد لجأ الباحث الى اجراء التكافؤ بين مجموعتي البحث والجدول (ب) يوضح ذلك .

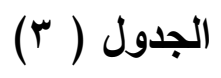

الوسط الحسابي والانحراف المعياري واختبار ( t ) للاعبي كرة اليد والسلة

\section{في المتغيرات البدنية}

\begin{tabular}{|c|c|c|c|c|c|}
\hline \multirow{2}{*}{ قالمسوية ت } & \multicolumn{2}{|c|}{ لاعبي كرة السلة } & \multicolumn{2}{|c|}{ لاعبي كرة اليا } & \multirow{2}{*}{ الاختبار } \\
\hline & $\varepsilon \pm$ & سَ & $\varepsilon \pm$ & 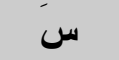 & \\
\hline $1, \lambda r$ & $\cdot, r r$ & $\varepsilon, \leqslant\rceil$ & $\cdot, r$ & $\varepsilon, r \leqslant$ & ركض ·r م من وضع الطائر · /ثا \\
\hline$r, \cdot r$ & $r, v r$ & $\varepsilon 0,1 r$ & $r, v r$ & $\varepsilon r, \tau$. & اختبار الققز العمودي /سم \\
\hline $1, .9$ & $\cdot, T V$ & $0,1 Y$ & •, Tr & $0, Y_{1}$ & رمي كرة طبية زنة r كغم من الجلوس/م \\
\hline$\cdot, 79$ & $1 \cdot, Y_{1}$ & $00, \varepsilon$ & $9, r$ & or, r & اختبار القزز العمودي المنكرر/ك \\
\hline$\cdot, \mathrm{V} \varepsilon$ &., OrT & $1 \cdot, 19$ & $\cdot$, OY & $1 \cdot, r$ & الجري الارتدادي ع × · ا م · /ثا \\
\hline • & $\cdot, r$ & $0, r \mu$ & $\cdot, \mu \wedge$ & $0,1 Y$ & اختبار الدوائر المرقمة /درجة \\
\hline
\end{tabular}

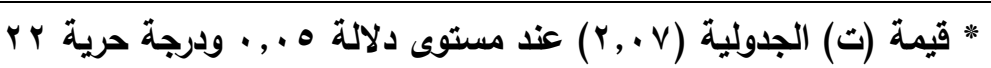

يتضـح مـن الجدول اعـلاه ان قيمـة (ت) المحسوبة كانت اقل مـن قيمـة (ت) الجدوليـة

ولجميع الاختبارات ـ مما يدل على عدم وجود فروق بين لاعبي كرة اليد والسلة في البدنية .

ومن ثم تكافؤ عينة البحث في المتغيرات البدنية . 
ب- ـ تحديد مؤشر القدرة الهوائية و اللاهو ائية :

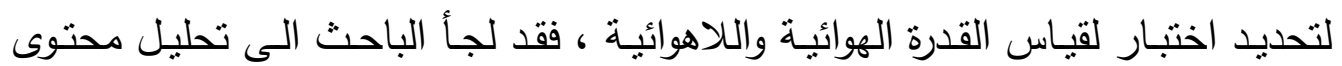

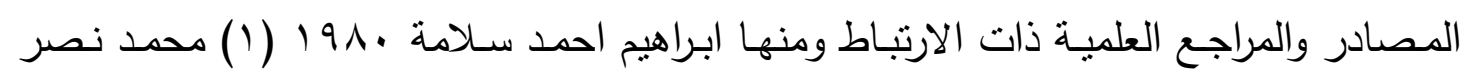

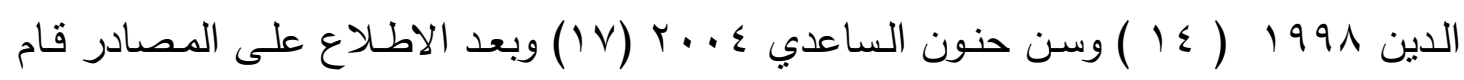

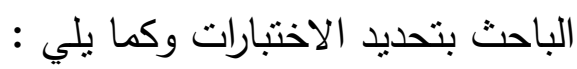

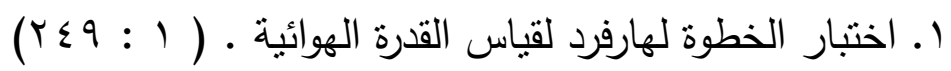

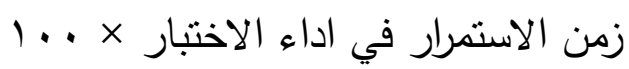

مؤشر الكفاءة البدنية =

× 0,0.

r. اختبار الوثب العمودي (الثغل) لقياس القدرة اللاهوائية ( ع ا : Y Y )

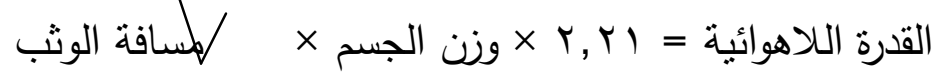

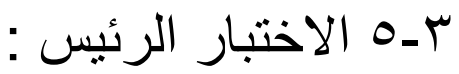
قبل اجراء الاختبار الرئيسي قام الباحث باتخـاذ جميع التدابير التي تكفل لـه نجاح الاختبار الرئيسي عن طريق اخذ الموافقات الاصولية من مسؤولي الفريقين وبما يتلاءم مع وقت

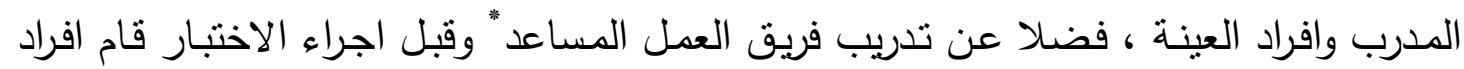

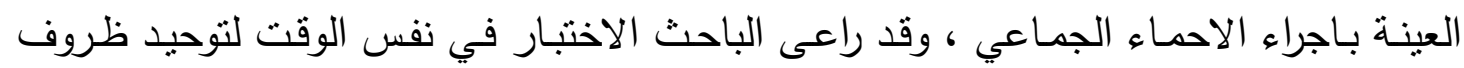
الاختبار وعلى مدى يومين حيث قام في اليوم الاول باختبار عينة البحث في اختبار الخطوة لهارفرد وفي اليوم الثاني تم اجراء اختبار الوثب العمودي (الثغل).

ب-7 المعالجات الاحصائية :

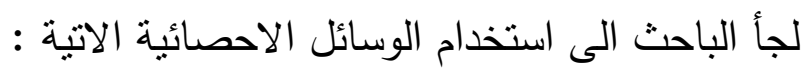

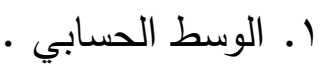
r. الانحراف المعياري . الحسيط $(Y V Y-1.1: 17)$ r. اختبار (ت ) . (تحرة

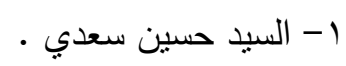

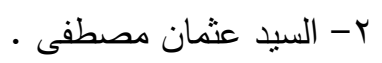

M19 


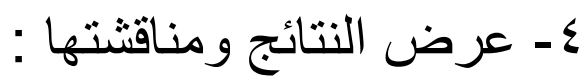

ع - أ عرض النتائج

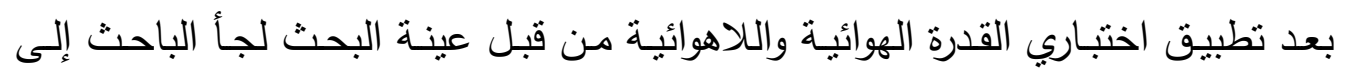

معالجتها إحصائيا لغرض التوصل إلى النتائج وكما موضح في أدناه :

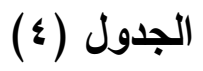

يوضح الوسط الحسابي والانحراف المعياري واختبار ( ت ) للقدرة الهوائية

وإللاهوائية بين لاعبي كرة اليد والسلة

\begin{tabular}{|c|c|c|c|c|c|}
\hline \multirow{2}{*}{ قالمسوية ت } & \multicolumn{2}{|c|}{ لاعبي كرة السلة } & \multicolumn{2}{|c|}{ لاعبي كرة اليد } & \multirow{2}{*}{ الاختبار } \\
\hline & $\varepsilon^{ \pm}$ & س & $\varepsilon \pm$ & س & \\
\hline$\cdot, \cdot I^{r}$ & T,TV & $\pi, \varepsilon 1$ & $r, \varepsilon r$ & $7 \cdot, 01$ & اختبار القدرة الهوائية .|درجة \\
\hline$\cdot, 1 \leq$ & $\mathrm{r}, \wedge \mathrm{V}$ & $\begin{array}{c}111,0 \\
\varepsilon\end{array}$ & $\varepsilon, Y V$ & $111, r 91$ & القدرة اللاهوائية./كغم متر ثا \\
\hline
\end{tabular}

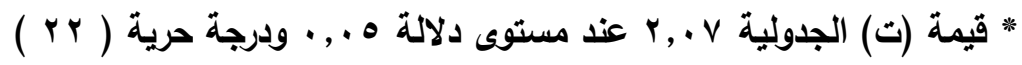

يتضح من الجدول (§) ان الوسط الحسابي لاختبار القدرة الهوائية للاعبي كرة اليد كان

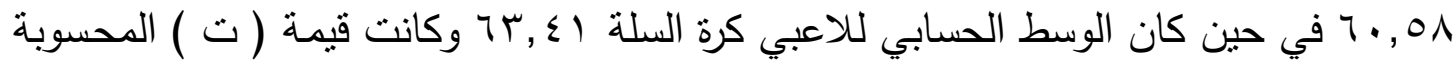

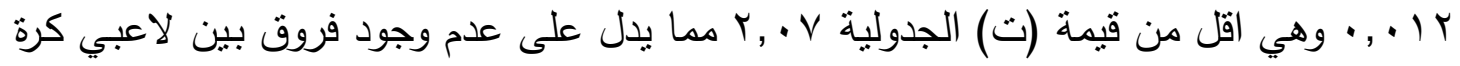

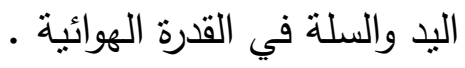

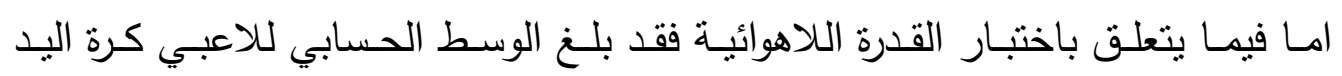

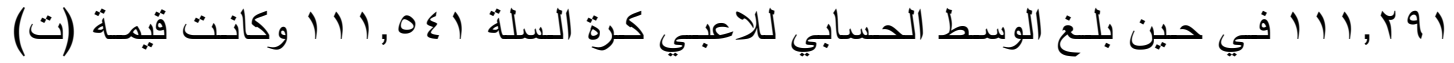

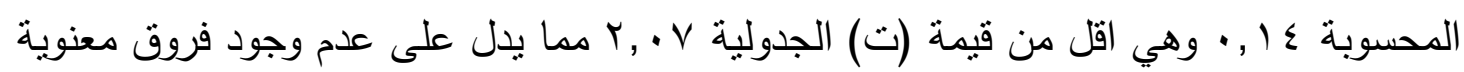

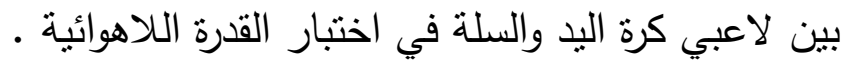

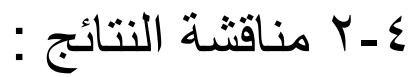

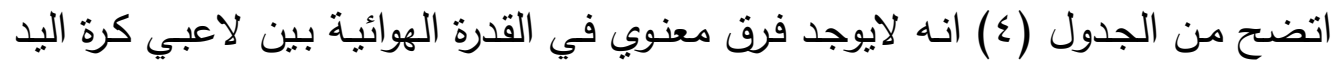

والسلة حيث كانت قيمة (ت) المحسوبة اقل من قيمة (ت) الجدولية كما اتضح كذللك ان لاندي لاعبي الفريقين هم بمستوى منوسط في القدرة الهوائية (المستوى المتوسط في القدرة الهوائية هو المستوى

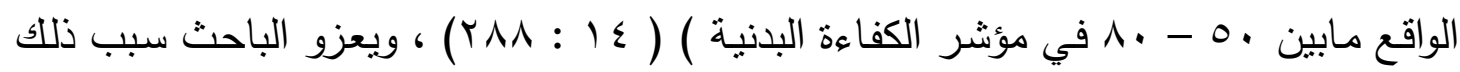

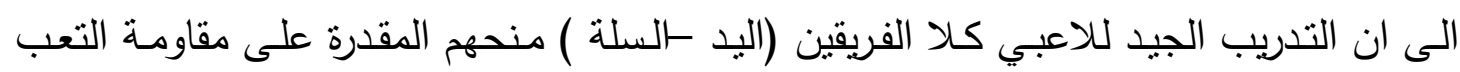


بشكل يضمن مستوى جيد من التحمل ، على اعتبار ان التحمل العام صفة اساسية تهدف الى

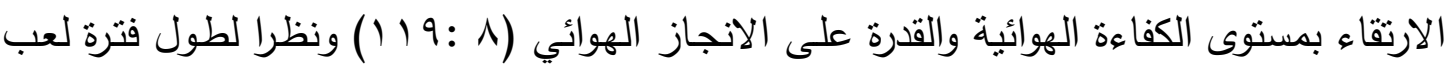

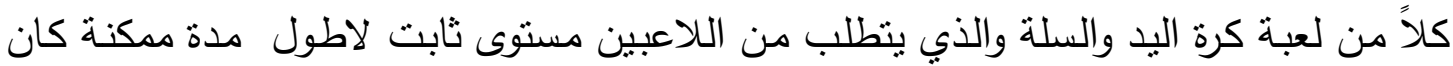

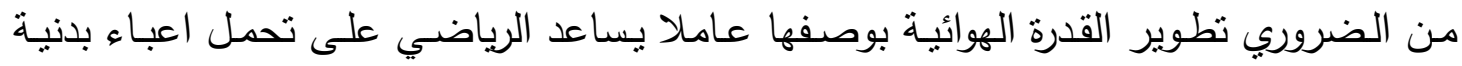

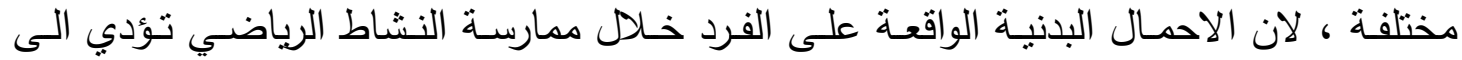

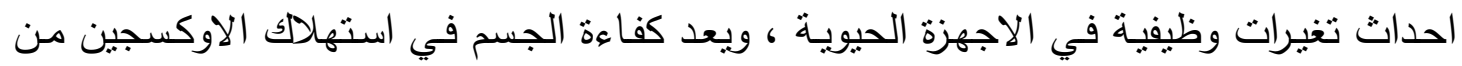

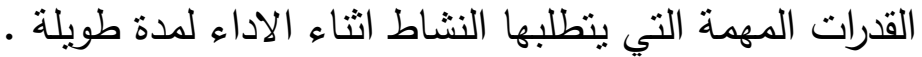

$(1 \vee \leqslant: 11)$

ويتضح كنلك من الجدول (ع) انه لايوجد فرق معنوي في القدرة اللاهوائية بين لاعبي

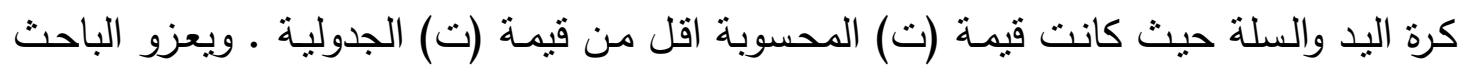

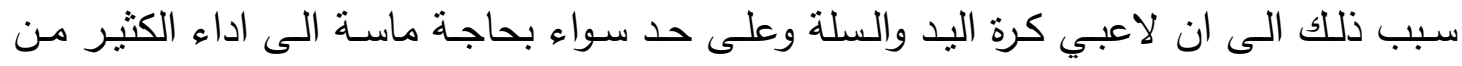
الحركات السريعة والدفاجئة والتي تفرضها طبيعة اللعب ، لذلك نجد ان التمرينات التي يستخدمها اللاعبين في اثثاء تدريباتهم تعمل على تطوير القدرة الانفجارية للرجلين والذراعين والتي تعمل في لني نطاق النظام الاول لانتاج الطاقة (ATP-CP) وهذا ما اكده الخبراء والمتخصصين في ان القوة الانفجارية للرجلين والذراعين هي احد اهم عناصر اللياقة البدنية لدى لاعبي كرة اليد والسلة ، الاهل

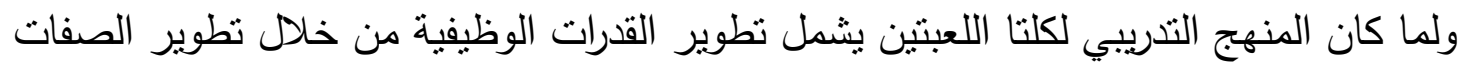
البدنية حتى ينعكس ذلك في المحصلة على اداء اللاعب ، حيث ان تدريبات القفز بانواعها هي لئي وسيلة لتتمية عمل الجهاز العضلي والعصبي كي يستجيب بقوة وبسرعة اكبر في اثتاء اداء حركات تتطلب مدا عضليا يتبعه مباشرة قصر في العضلة ، وان تطوير الاستجابة السريعة للعضلات كرد فعل منعكس تقوم به مغازل العضلات ، وهذا يعكس مدى التوافق الجيد داخل

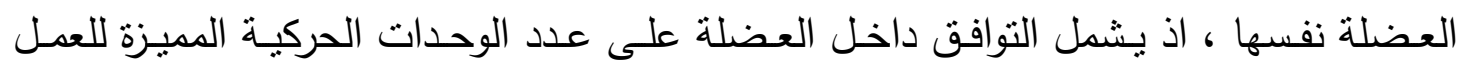

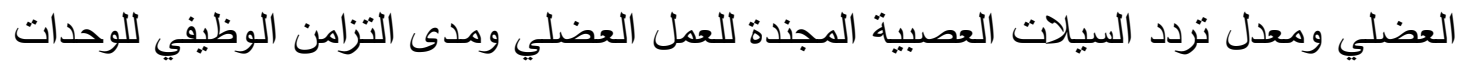
الحركية المستخدمة في العمل العضلي ، وهذا بدوره يعمل على تطوير قدرة العضلات العاملة

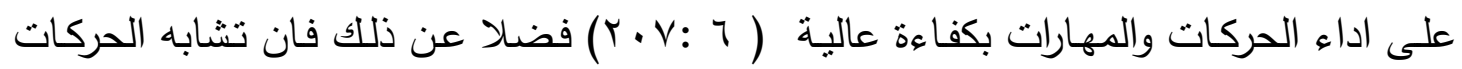

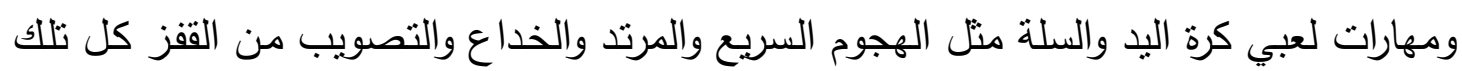
المهارات والحركات تتطلب شدة قصوى وزمن اداء قصبر جدا وذلك يعني اعتمادها على القدرة

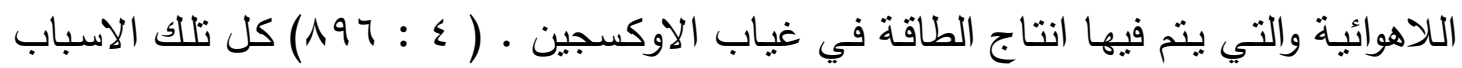
جعلت الفروق بين لاعبي كرة اليد والسلة في القدرة اللاهوائية غير معنوية . 


$$
\begin{aligned}
& \text { 0ـالاستتناجات و التوصيات : } \\
& \text { 0ـ الاستنتاجات : }
\end{aligned}
$$

ا ـ لا توجد فروق ذات دلالة معنوية في القدرة الهوائية بين لاعبي كرة اليد والسلة .

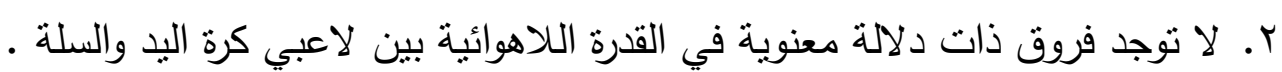
r. لاعبي كلا الفريقين اليد والسلة هم في مستوى متوسط في القدرة الهوائية .

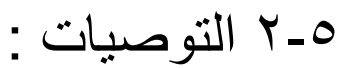

ا ـ التأكيد على استخدام مؤشر القدرة الهوائية واللاهوائية لاهميته في عكس الحالة الصحية

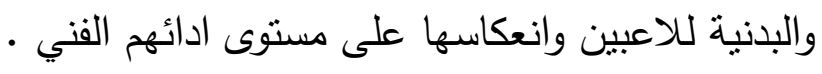

r. التأكيد في البرامج التدريبية على تطوير القدرة الهوائية واللاهوائية وبما يتتاسب مع التهائ المرحلة

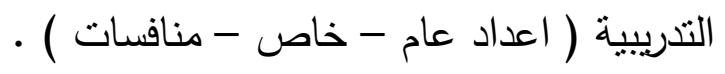

r. اجراء دراسات مشابهة باستخدام القدرة اللاهوائية اللاكتيكية .

ع. اجراء دراسات مشابهة وعلى فعاليات فردية ( تتس - ساحة وميدان ) او على فرق نسوية . 0. اجراء دراسات مقارنة في القدرات الهوائية واللاهوائية بين فعاليات فردية واخرى فرقية. 
المصادر

ا ـ ابراهيم احمد سلامة : الاختبارات والقياس للتربية البدنية ، دار المعارف ، القاهرة ، .919 1 .

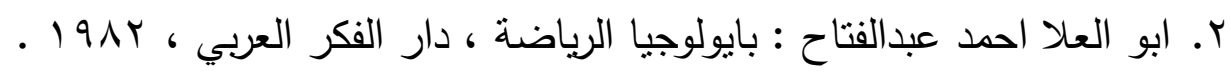
r. احمد عبدالغني طه : التحليل الزمني والفسلجي للاداءات الحركية في فعاليتي سـلاح الثيش وسيف المبارزة رسالة ماجستير غير منشورة ، جامعة الموصل ، 199V . ع. اخلاص نور الدين واخرون : ناثير كل من التدريب اللاهوائي والتدريب الهوائي بالحبل على الكفاءة الوظيفية لطالبات كلية التربية الرياضية ، بحوث المؤتمر العلمي الاول ، المجلد ب جامعة حلوان $191 \mathrm{~V}$ ه. بسطويسي احمد بسطويسي : اسس ونظريات التدريب الرياضي ، دار الفكر العربي ، القاهرة . 1999

7. حسن عبدالقادر عصري : دراسـة مقارنـة لبعض مؤشـرات القدرة الهوائيـة واللاهوائيـة بـين لاعبي الخطوط المختلفة بكرة القدم ، اطروحة دكتوراه غير منشورة ، جامعة بغداد ، 999

V. طلحـة حسام الدين : الاسـس الحركيـة والوظيفيـة للتدريب الرياضسي ، دار الفكر العربـي،

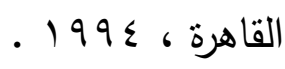

^. عادل عبدالبصير : التدريب الرياضي والتكامل بين النظرية والتطبيق ، ط ا ، مركز الكتاب للنشر ، القاهرة ، 1999

9. محمد حسن علاوي ، محمد نصر الدين رضوان : الاختبارات المهارية والنفسية في المجال

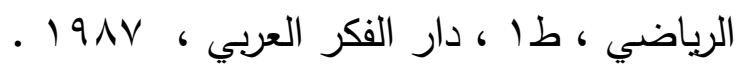

• (. محمد حسن عـلاوي ، محمد نصر الدين رضـوان : اختبارات الاداء الحركي ، دار الفكر

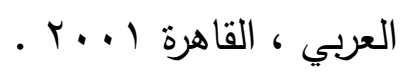

ا ا.محمد صبحي حسانين : التقويم والقياس في التربيـة الرياضـية ، جا ، طـ ، دار الفكر

$$
\text { العربي ، القاهرة ، } 1990
$$

ץ ا ـمحمد عبدالغني عثــان : التعلم الحركي والتدريب الرباضـي ، دار القلم للنشر والتوزيـع ،

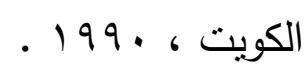

سا ـمحمد مرعي علي محمد : اثر التدريب الفتري باستخدام ازمنة مختلفة من منطقة الجهد الاولى في بعض المتغيرات البدنية والمهارية ومعدل سرعة النبض لدى لاعبي كرة السلة ،

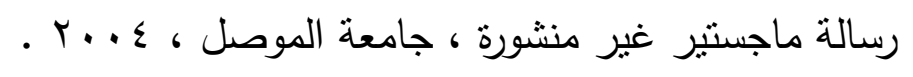
ع ا ـمحمد نصر الدين رضوان : طرق قياس الجهد البدني في الرياضـة ، طا ، مركز الكتاب للنشر ، القاهرة ، 1991 
ه ا نبيل محمد الشاروك : دراسـة مقارنـة في بعض عناصر اللياقة البدنيـة بين لاعبي المراكز المختلفة بكرة السلة ، رسالة ماجستير غير منشورة ، جامعة الموصل ، .99 1. 7 ا. وديع ياسين ، حسن محمد عبد : التطبيقات الاحصائية في بحوث التربية الرباضية ، دار الكتب للطباعة والنشر ، جامعة الموصل ، 1997 ، 199 V ا ـوسن حنون الساعدي : منهج تدريبي باستخدام مؤشر النبض وتأثيره في متغيرات فسيولوجية وكيميائية وعلاقته باداء مهارات هجومية في كرة السلة ، رسالة دكتوراه غير منشورة ، جامعة

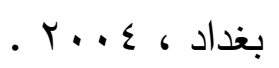

18.Mcardel W.D. \& at. al. : "Exercise physiology" ( 4 thed ) William \& Wilkins pub , Philadelphia, 1996. 